\title{
QUALITY OF LIFE IN ADULT PATIENTS TREATED WITH PERIPHERAL BLOOD PROGENITOR CELL TRANSPLANTATION: THE EFFECT OF SELECTED PSYCHOSOCIAL, DEMOGRAPHICS AND HEALTH ASPECTS ON QUALITY OF LIFE: A RETROSPECTIVE ANALYSIS
}

\author{
Ladislav Slováček ${ }^{1,2}$, Birgita Slováčková ${ }^{3}$, Ladislav Jebavỹ ${ }^{1,4}$, Vladimír Pavlik $^{5}$ \\ University of Defence, Faculty of Military Health Science Hradec Králové, Czech Republic: Department of Field Internal \\ Medicine $^{1}$, Department of Field Hygiene ${ }^{5}$; Charles University in Prague, Faculty of Medicine and University Hospital in \\ Hradec Králové, Czech Republic: Department of Oncology and Radiotherapy ${ }^{2}$, Department of Psychiatry ${ }^{3}, 2^{\text {nd }}$ Department \\ of Medicine, Division of Clinical Haematology 4
}

Summary: Aim: this retrospective study analyses the effect of selected psychosocial, demographics and health aspects on quality of life $(\mathrm{QoL})$ in adult patients treated with peripheral blood progenitor cell transplantation (PBPCT). Patients and Methods: The total number of respondents treated with PBPCT between the years 2001-2003 was 95. The return rate of QoL questionnaires was $72.1 \%$ (71 respondents). There were $100 \%$ ratable QoL questionnaire. The average age of all respondents was 55.5 years old. The Czech version of an international generic European Quality of Life Questionnaire Version EQ-5D was used. The effect of selected aspects on QoL of patients was determined by analysis of variance. The QoL questionnaires were evaluated with descriptive analysis. Results: The above-mentioned aspects proved statistically significant dependence of QoL (EQ-5D score - QoL dimensions, EQ-5D VAS - subjective health condition) on age, increasing number of associated diseases, religion and type of disease. The effect of other aspects on QoL was not proven statistically significant. The QoL in adult patients treated with PBPCT declines with increasing age and with the increasing number of associated diseases. People of faith have a higher level of QoL than non-believers. Patients with multiple myeloma treated with PBPCT have the most low QoL. Conclusion: The global QoL in an adult patients treated with PBPCT is on a good level.

Key words: Quality of life; Peripheral blood progenitor Cell transplantation; Quality of life questionnaires

\section{Introduction}

The quality of life $(\mathrm{QoL})$ is defined as "a patient's subjective evaluation of his life situation" $(11,13,20)$. The QoL term contains the information on an individual's physical, psychological, social and spiritual condition $(11,13)$. The QoL evaluation is carried out by means of generic and specific questionnaires $(11,13,20)$. Generic questionnaires generally evaluate a patient's overall condition regardless of his disease. Specific questionnaires are designed for the evaluation of a patient's overall condition in a particular type of disease. Modules are often used with these specific questionnaires. These modules are focused on specific symptoms and complaints in a particular type of disease $(11,13,20)$.

The haematopoietic stem cell transplantation (HSCT) is a modern therapeutic method used for biomodulation anti-tumour therapy of haematological malignities and of selected solid tumours. It is also used for the therapy of non-tumour and hereditary diseases $(1,3,12)$. It is divided into bone marrow transplantation (BMT), the transplantation of stem (progenitor) cells (PBPCT) and umbilical cord blood transplantation (UCBT). From a donor's point of view there are three kinds of transplantations: syngenic transplantation (the donor is a monozygotic twin), allogeneic transplantation (HLA - human leukocytes antigen from a compatible sibling or parent or HLA from a compatible donor) and autologous transplantation (patient is his/her own donor). The aim of the HSCT is to replace a patient's pathological bone marrow which contains tumorous cells, with haematopoietic cells from a healthy donor and to restore haematopoiesis, which is damaged by an intensive anti-tumour therapy $(1,3,12)$. The HSCT influences the further course of disease, and by this the quality of life $(\mathrm{QoL})$ for patients in the same way as other therapeutic methods (20).

The aim of the current QoL study was to analyse the effect of selected demographic, psychosocial and health 
aspects on QoL in adult patients with haematological malignancy treated with PBPCT and to evaluate global QoL in this cohort of patients.

\section{Design of study}

The study is a retrospective and it is based on data obtained during year 2004 / 2005 (from September 1, 2004 to January 31, 2005) in 95 adult patients treated with PBPCT between the years 2001-2003 in the Department of Clinical Haematology of $2^{\text {nd }}$ Department of Medicine of Charles University Hospital and Faculty of Medicine in Hradec Králové, Czech Republic.

The study was approved the Ethics Commission of the Charles University Hospital and Faculty of Medicine in Hradec Králové, Czech Republic.

\section{Material and methods}

\section{Group characteristics}

The total number of adult patients treated with PBPCT from 2001 to 2003 was 171 (135 patients treated with autologous PBPCT and 36 patients treated with allogeneic PBPCT). The total number of respondents was 95 (60 patients died and 16 patients were after retransplantation). The return rate of QoL questionnaires was $72.1 \%$ (71 respondents) and we could evaluate $100 \%$ of them.

The number of respondents treated with PBPCT from 2001 to 2003 was as follows: in 2001: 20 respondents (10 male and 10 female), their average age was 55.5 years old, in 2002: 20 respondents ( 10 male and 10 female), their average age was 55.0 years old, in 2003: 31 respondents (19 male and 12 female), their average age was 55.5 years old. Out of the total number of 71 respondents, 66 respondents were treated with autologous PBPCT and 5 respondents were treated with allogeneic PBPCT (in 2001 there was no respondent with allogeneic PBPCT, in 2002 there were 2

Tab. 1: Number of respondents according to the type of PBPCT.

\begin{tabular}{|l|c|c|c|c|}
\hline Type of PBPCT & 2001 & 2002 & 2003 & $\begin{array}{c}\text { Total } \\
\text { number }\end{array}$ \\
\hline Autologous PBPCT & 20 & 18 & 28 & 66 \\
\hline Allogeneic PBPCT & 0 & 2 & 3 & 5 \\
\hline
\end{tabular}

Tab. 2: Number of respondents according to the type of diseases.

\begin{tabular}{|l|c|c|}
\hline Type of disease & $\begin{array}{c}\text { Number } \\
\text { of } \\
\text { respondents }\end{array}$ & $\begin{array}{c}\text { Autologous/ } \\
\text { allogeneic } \\
\text { PBPCT }\end{array}$ \\
\hline Hodgkin's lymphoma & 9 & $7 / 2$ \\
\hline non-Hodgkin's lymphoma & 15 & $15 / 0$ \\
\hline Acute lymphoblastic leukaemia & 2 & $2 / 0$ \\
\hline Acute myeloid leukaemia & 12 & $9 / 3$ \\
\hline Chronic myeloid leukaemia & 1 & $1 / 0$ \\
\hline Multiple myeloma & 32 & $32 / 0$ \\
\hline
\end{tabular}

respondents and in 20033 respondents). In the group of patients with allogeneic PBPCT, 3 patients had the mucocutaneous form of chronic graft-versus-host disease (cGVHD). These were patients with acute myeloid leukaemia. Tables 1 and 2 show the representation of respondents treated with PBPCT according to the type of transplantation and according to the type of disease.

\section{Instrument}

The Czech version of an international generic European Quality of Life Questionnaire - Version EQ-5D (EuroQol EQ-5D) was used $(20,22)$. This questionnaire evaluates 2 indicators: objective and subjective indicators. The objective indicator includes 5 dimensions of QoL: mobility, selfcare, usual activities, pain (discomfort and anxiety) depression. Three kinds of answers, which express the degree of complaints, are offered to each question (no complaints, mild complaints, severe complaints). A total of 243 $\left(3^{5}\right)$ combinations of health conditions exits. The outcome is the EQ-5D score (dimensions of QoL), which has values from 0 to 1 ( 0 - the worst health condition, 1 - the best health condition). The subjective indicator includes a visual analogous scale (a value of 100 - the best health condition, a value of 0 - the worst health condition) $(20,22)$. The respondent marks his subjectively perceived health condition on the thermometer scale. The outcome is EQ-5D VAS (a subjective health condition), which has values from 0 to $100(20,22)$.

\section{Procedure}

The Euro Qol EQ-5D Questionnaire, with a covering letter in which the whole project was explained, together with a stamped envelope, were mailed to a respondents address. Filling in the QoL questionnaire was voluntary and anonymous.

\section{Data collection, statistical methods}

The Euro Qol EQ-5D evaluates 2 indicators, objective (EQ-5D score) and subjective (EQ-5D visual analoques scale). The outcome is the EQ-5D score (dimensions of QoL), which has the values from 0 to 1 ( 0 - the worst health condition, 1 - the best health condition). The subjective indicator (EQ-5D VAS) includes the visual analogous scale (the value of 100 - the best health condition, the value of 0 - the worst health condition). The evaluation of QoL questionnaires was carried out by means of descriptive analysis in accordance with European Quality of Life Group Methodology (20, 22). The independent variables were age, sex, level of education, marital status, increasing number of associated diseases, smoking abuse, religion, type of PBPCT and time lapse from PSCT. We did not monitor the effect of chronic Graft Versus Host Disease on the QoL of patients treated with allogeneic PBPCT because of the small amount of patients in the collection. The dependent variables were the EQ-5D score (dimensions of QoL) and the EQ-5D VAS (a subjective health condition). 
The basic statistical characteristics were fixed (mean value, standard deviation, maximum and minimum value) for all responses. The effect of selected aspects on QoL of adult patients was evaluated by means of analysis of variance (ANOVA). A value of $\mathrm{P}<0.05$ (5\%) was considered significant. Software StatSoft STATISTICA Base Version 7.1 for windows was used for analysis.

\section{Results}

The above-mentioned aspects proved a statistically significant dependence of QoL (EQ-5D score and EQ-5 VAS) on age (in both cases $\mathrm{p}<0,01$ ), increasing number of associated diseases (in both cases $\mathrm{p}<0,01$ ), religion (in both cases $p<0,01$ ) and type of disease (in both cases $p<0,05$ ). EQ-5D score (dimensions of QoL) and EQ-5D VAS (a subjective health condition) significantly decrease with increasing age and increasing number of associated diseases (see Tab. 3, 4). These values are significantly higher in patients who believe in God compared to patient without religious beliefs (see Tab. 5). They are most significantly high in patients with malignant lymphoma and with acute myeloid leukaemia and most low in patients with multiple myeloma (see Tab. 6). The mean EQ-5D score was $68.9 \%$ and mean EQ-5D VAS was $66.6 \%$, and in patients with malignant lymphoma and acute leukaemia the mean EQ-5D score was $82.7 \%$ and mean EQ-5D VAS was $76.7 \%$.

Tab. 3: Comparison of mean EQ-5D score and EQ-5D VAS values in individual age groups $(n=71, p<0,05)$.

\begin{tabular}{|c|c|c|c|c|c|}
\hline $\begin{array}{c}\text { Age } \\
\text { range }\end{array}$ & $\begin{array}{c}\text { Number } \\
\text { of } \\
\text { respon- } \\
\text { dents }\end{array}$ & $\begin{array}{c}\text { Mean } \\
\text { values of } \\
\text { EQ-5D } \\
\text { score } \\
\text { (in \%) }\end{array}$ & $\begin{array}{c}\text { Standard } \\
\text { devia- } \\
\text { tion }\end{array}$ & $\begin{array}{c}\text { Mean } \\
\text { values of } \\
\text { EQ-5D } \\
\text { VAS } \\
\text { in \%) }\end{array}$ & $\begin{array}{c}\text { Standard } \\
\text { devia- } \\
\text { tion }\end{array}$ \\
\hline $20-29$ & 6 & 93.3 & 11.4 & 79.2 & 13.6 \\
\hline $30-39$ & 8 & 96.2 & 5.3 & 85.0 & 8.4 \\
\hline $40-49$ & 11 & 89.6 & 12.7 & 76.2 & 15.6 \\
\hline $50-59$ & 23 & 70.2 & 15.4 & 67.0 & 14.0 \\
\hline $60-69$ & 17 & 65.4 & 9.5 & 64.1 & 13.7 \\
\hline $70-79$ & 6 & 57 & 9.6 & 64.5 & 11.1 \\
\hline
\end{tabular}

Tab. 4: Comparison of mean EQ-5D score and EQ-5D VAS values in an increasing number of associated diseases $(n=71$, $\mathrm{p}<0.05)$.

\begin{tabular}{|c|c|c|c|c|c|}
\hline $\begin{array}{c}\text { Number } \\
\text { of } \\
\text { diseases }\end{array}$ & $\begin{array}{c}\text { Number } \\
\text { of } \\
\text { respon- } \\
\text { dents }\end{array}$ & $\begin{array}{c}\text { Mean } \\
\text { values of } \\
\text { EQ-5D } \\
\text { score } \\
\text { (in \%) }\end{array}$ & $\begin{array}{c}\text { Standard } \\
\text { devia- } \\
\text { tion }\end{array}$ & $\begin{array}{c}\text { Mean } \\
\text { values of } \\
\text { EQ-5D } \\
\text { VAS } \\
\text { (in \%) }\end{array}$ & $\begin{array}{c}\text { Standard } \\
\text { devia- } \\
\text { tion }\end{array}$ \\
\hline 0 & 30 & 83.9 & 16.4 & 76.3 & 12.4 \\
\hline 1 & 13 & 74.7 & 18.8 & 71.5 & 18.4 \\
\hline 2 & 14 & 70.9 & 15.2 & 66.2 & 13.0 \\
\hline 3 & 7 & 71.0 & 12.8 & 67.1 & 12.9 \\
\hline$>3$ & 7 & 56.7 & 11.4 & 57.1 & 14.7 \\
\hline
\end{tabular}

The global QoL of patients treated by means of PBSCT in the Department of Clinical Haematology of $2^{\text {nd }}$ Department of Internal Medicine of Charles University Hospital and Faculty of Medicine in Hradec Králove, Czech Republic, is on a good level, which is seen from the EQ-5D score (mean value of EQ-5D score of all respondents was $72.5 \%$ ) and EQ-5D VAS (mean value of EQ-5D WAS was $76.5 \%$ ) values.

\section{Discussion}

HSCT is a therapeutic modality used in antitumorous treatment of haematological malignancies as well as solid tumors. Apart from that it is also used in the therapy of non-malignant and hereditary diseases $(1,3,12,20)$. The process of HSCT is quite challenging for patients for seve-

Tab. 5: Comparison of mean EQ-5D score and EQ-5D VAS values with religion $(n=71, p<0.05)$.

\begin{tabular}{|c|c|c|c|c|c|}
\hline Religion & $\begin{array}{c}\text { Number } \\
\text { of } \\
\text { respon- } \\
\text { dents }\end{array}$ & $\begin{array}{c}\text { Mean } \\
\text { values of } \\
\text { EQ-5D } \\
\text { score } \\
\text { (in \%) }\end{array}$ & $\begin{array}{c}\text { Standard } \\
\text { devia- } \\
\text { tion }\end{array}$ & $\begin{array}{c}\text { Mean } \\
\text { values of } \\
\text { EQ-5D } \\
\text { VAS } \\
\text { (in \%) }\end{array}$ & $\begin{array}{c}\text { Standard } \\
\text { devia- } \\
\text { tion }\end{array}$ \\
\hline Believers & 43 & 85.6 & 12.9 & 76.6 & 12.8 \\
\hline $\begin{array}{c}\text { Non- } \\
\text { believers }\end{array}$ & 28 & 60.4 & 11.9 & 57.6 & 12.9 \\
\hline
\end{tabular}

Tab. 6: Comparison of respondents with multiple myeloma, malignant lymphoma and acute leukaemia treated with PBPCT according to the level of troubles.

\begin{tabular}{|c|c|c|c|}
\hline $\begin{array}{l}\text { Dimension } \\
\text { of QoL }\end{array}$ & $\begin{array}{l}\text { Level of } \\
\text { evaluation }\end{array}$ & $\begin{array}{l}\text { Malignant } \\
\text { lymphoma } \\
\text { and acute } \\
\text { myeloid } \\
\text { leukaemia }\end{array}$ & $\begin{array}{l}\text { Multiple } \\
\text { myeloma }\end{array}$ \\
\hline $\begin{array}{l}\text { Number } \\
\text { of Respondents }\end{array}$ & & rel & Rel. \\
\hline \multirow[t]{3}{*}{ Mobility } & none troubles & $70.8 \%$ & $41 \%$ \\
\hline & with troubles & $29.2 \%$ & $59 \%$ \\
\hline & immobile & 0 & 0 \\
\hline \multirow[t]{3}{*}{ Self-care } & none troubles & $91.7 \%$ & $81.2 \%$ \\
\hline & with troubles & $8.3 \%$ & $18.8 \%$ \\
\hline & incapable & 0 & 0 \\
\hline \multirow[t]{3}{*}{ Usual activities } & none troubles & $70.8 \%$ & $18.8 \%$ \\
\hline & with troubles & $25.0 \%$ & $81.2 \%$ \\
\hline & incapable & $4.2 \%$ & 0 \\
\hline \multirow[t]{3}{*}{ Pain / Discomfort } & none & $66.7 \%$ & $28.1 \%$ \\
\hline & weighty & $33.3 \%$ & $68.8 \%$ \\
\hline & extremely & 0 & $3.1 \%$ \\
\hline \multirow[t]{3}{*}{ Anxiety / Depression } & none & $75.0 \%$ & $41 \%$ \\
\hline & weighty & $20.8 \%$ & $59 \%$ \\
\hline & extremely & $4.2 \%$ & 0 \\
\hline $\begin{array}{l}\text { Number } \\
\text { of Respondents }\end{array}$ & & 38 & 32 \\
\hline
\end{tabular}


ral reasons. First of all, there are unwanted effects of systematic chemotherapy, repetitive invasive performances central and peripheral vein catetrization, diagnostic aspiration of bone marrow and so on. In men, it is also a question of sperm taking followed by cryoconservation of seminal fluid because of the possibility of reproductive organs dysfunction caused by intensive antitumorous therapy (permanent or temporary infertility). Hormonal substitutional therapy is indicated in young females because of possibility of damaging the reproductive organs. We also have to consider several weeks of isolation in a sterile box. There is increased sensibility to opportunive infections (bacterial, viral, fungal, mycoplasmatic etc.) as an affect of bone marrow toxicity caused by high-dose chemotherapy. Beside those symptoms, the patient is loaded with results of toxicity caused by high dose chemotherapy (mucositis, gastroenteritis, dermatitis, alveolitis, signs of cardiotoxicity and neurotixicity). A serious complication is acute or chronic graft-versus-host disease (GVHD), which is the result of allogeneic transplantation (from a relative or non-relative donor). Acute GVHD especially affects the liver, mucosa of intestinal tract and skin. Serious forms can cause death. Chronic GVHD damage, particularly intestinal tract and skin, can handicap the patient. By listing all possible risks and complications, it is necessary to mention that highdose chemotherapy followed by HSCT can not $100 \%$ ensure by, that all malignant cells will be eliminate. There is a possibility of relapse and as an optional treatment we can again choose high dose chemotherapy followed by HSCT $(1,3,6,12,16,20)$.

In our QoL study, we found three main outcomes in subjective well-being patients who were able to undergo high-dose chemotherapy supported by autologous PBPCT.

First, our results show that a lower QoL correlates with increasing age of patients treated by means of PBPCT. We think that increasing age correlates with an increasing number of associated diseases. The QoL of patients with increasing age should be stressed. Also, we think that increasing overall fatigue and emotional complaints, which decrease the QoL, correlate with increasing age. De Souza (8) points this out in his longitudinal study conducted on a group of 26 patients. Also, this author (8) further explained his statements by the fact that with increasing age a number of associated diseases can occur. These diseases reduce the QoL (8). Choidi (7) also agrees with this opinion in his transversal study conducted on a group of 244 patients with haematological malignancy who underwent allogeneic BMT. This author (7) also points out the fact that, in addition to the number of associated diseases, the negative effects of chronic Graft Versus Host Disease (cGVHD) on a lower QoL in patients with increasing age should be stressed. Wang (24), Wong (25) and Andrykowski (2) also agree with the negative influence of cGVHD on QoL in patients with increasing age. Zittoun (26) discovered another interesting piece of information in his transversal study conducted on a group of 179 patients with haematological malignancy who underwent HSCT. He points out that increasing overall fatigue and emotional complaints, which decrease the QoL, correlate with increasing age (26). So (21) also discovered an interesting piece of information in his transversal study conducted on a group of 157 patients with haematological malignancy who underwent BMT. He proved a high degree of overall fatigue in patients over the age of 50 with associated diseases (21).

Second, our results show that a lower QoL correlates with an increasing number of associated diseases. We think that with the increasing number of associated diseases correlating with overall fatigue along with emotional difficulties in patients with an increasing number of associated diseases, there is lower overall physical fitness. This causes a lower QoL. Zittoun (26) discovered an interesting piece of information which showed the correlation among an increasing number of associated diseases, overall fatigue and emotional difficulties. Molassiotis (18) also agrees in his longitudinal study, conducted on a group of 40 patients after BMT, with the opinion concerning emotional lability. He evaluated the emotional lability of these patients by means of Emotional Difficulties Scale (EDS) (18). This scale was presented to patients before the BMT. Another scientist who agreed with this opinion was So (21) in his transversal study conducted on a group of 157 patients with hematological malignities after BMT. He proved a high degree of overall fatigue in patients over the age of 50 with associated diseases. Patients were tested by means of Fatigue Scale - Chinese Version. Saleh (19) also agrees in his transversal study conducted on patients after HSCT with Zittoun's (26) and So's (21) opinions. This author stresses the fact that in patients with an increasing number of associated diseases there is a lower overall physical fitness, and this causes a lower QoL. Heinonen $(14,15)$ recorded in his longitudinal study, conducted on a group of 109 patients after allogeneic BMT, a lower QoL in patients in connection with an increasing number of associated diseases, increased morbidity, increasing overall fatigue and worse quality of sleep. When he compared polymorbid men and women after allogeneic BMT, he discovered a lower QoL in women $(14,15)$. Edman (9) arrived at similar conclusions in his transversal study conducted in the group of 25 Swedish patients after allogeneic PBSCT. He states that an increasing number of associated diseases is associated with greater physical complaints, increased morbidity, emotional lability (anxiety and depression), sexual problems and sleep disorders (9). Patients were divided into 3 groups and then tested. The first group was tested by means of a generic Sickness Impact Profile (SIP). The second group was tested by means of Frequency Intensity and Distress Scale (SFID-BMT) and the third group by means of Sense of Coherence Scale (SOC). All three questionnaires evaluate subjective functional condition, physical complaints and the ability to cope with a particular disease. Patients were tested 2 years after allogeneic PBPCT. Edman (9) found no differences in the QoL evaluation in patients after HSCT. 
However, physical complaints, sexual problems, increased morbidity, anxiety, depression and sleep disorders were recorded in all three questionnaires and in more than half of the patients. In the same way as Heinonen $(14,15)$, he points out that the above-mentioned complaints are connected with an increasing number of associated diseases.

Third, it is clear from our results that the QoL of patients treated by means of PBSCT and believing in God was higher than in patients who were non-believers. We think that the non-believing patients have to stop various activities, including interests and hobbies. Entonen (10) and Bach (4) recorded these changes in values in patients after BMT. The above-mentioned changes often mean that the patient has to stop various activities, including his interests and hobbies (4). Boyd (5) proved significant changes in patients after HSCT who believed in God. Patients who believed in God had a higher QoL than non-believers (5).

Fourth, we confirmed in our retrospective study a statistically significant dependence of QoL of adult patients treated by means of PBPCT on the type of disease. We found a most low QoL in the cohort of patients with multiple myeloma and most high QoL in the cohort of patients with malignant lymphoma and acute leukaemia treated by means of PBPCT. Prevailing complaints in the cohort of patients with multiple myeloma were: 1 . regular activity with complaints $81.2 \%$, 2. medium serious pain / discomfort $68.8 \%$, 3. movement with complaints $59 \%$, 4. medium serious anxiety / depression $59 \%$. Prevailing complaints in the cohort of patients with malignant lymphoma and acute leukaemia were: 1 . medium serious pain / discomfort $33.3 \%$, 2. movement with complaints $29.2 \%$, regular activity with complaints $25 \%$, medium serious anxiety / depression $20.8 \%$.

\section{Conclusion}

In summary, our study is the first probe in QoL of adult patients treated by means of PBSCT in our country. We are glad that the global QoL of our adult patients treated by means of PSCT is on a good level. Yet we understand that the data interpretation is not unambiguous, and for a more exact evaluation of our patients' QoL it would be useful to carry out a longitudinal study.

This study has limitations. The first is that study deals only with the effect of selected aspects on the QoL. We could add a few other aspects but we decided for these aspects because patients were able and willing to provide this information in a retrospectively and anonymously carried out study. The second is that we used only generic Euro Qol EQ-5D for evaluation of QoL of adult patients in our study. We decided for its evaluation because our patients were able and willing to complete only this QoL questionnaire. Our patients emphasized that this questionnaire was very intelligible and especially brief. We could use the originaly Czech version of Functional Assessement of Cancer Treatment - General Version (FACT - G) Questionnaire or EORTC QLQ-C30, but our patients responded negatively in terms of completing one of these QoL questionnaires. The patients emphasized that this QoL questionnaires is very comprehensive and time consuming. The third that the small collection of patients undergoing allogeneic PBPCT. The fourth is the limited information about the effect of selected aspects, especially religion, on QoL of patients treated by means of PBPCT in literature reviews for extensive discussion.

The dimensional module of QoL represents a manifold approach to a number of life aspects. The affection of several aspects could vary, because they depend on the phase of the disease and treatment. These findings show our knowledge about patient needs in a different perspective and could significantly contribute to the improvement of health care. They also can discover mechanisms which modify the disease origin and process $(17,20)$.

\section{Acknowledgements}

The study was supported by research project of the Ministry of Defence of the Czech Republic No. FVZ0000503.

\section{References}

1. Anděl M. Internal Medicine - Part IIIb - Haematology. 1 st. edc. Praque: Galen, 2001

2. Andrykowski MA, Greiner CB, Altmaier EM: Quality of life following bone marrow transplantation: finding from a multicentre study. J Cancer 1995;71:1322-9.

3. Atkinson K et al. The BMT Data Book: A Manual for Bone Marrow and Blood Stem Cell Transplantation. Cambridge: University Press, 1998:582.

4. Bach K et al. A method to improve nursing care and its effect on the rehabilitation of patients undergoing autologous bone marrow transplantation. EBMT Nurses Group Journal 1995;1:36-8.

5. Boyd C. Quality of Life: patient education for bone marrow transplant patients Is it more effective if your patient is a health care professional? EBMT Nurses Group Journal 1994;1:16-20.

6. Chang G, Orav EJ, Tong MY, Antin JH. Predictors of 1-year survival assessed at the time of bone marrow transplantation. Psychosomatics 2004:45:378-85.

7. Chiodi S, Spinelli S, Ravera C. Quality of life in 244 recipients of allogeneic bone marrow transplantation. Br J Haematol 2000;10:614-19.

8. De Souza CA, Duraes MI, Vigorito AC. Quality of life in patients randomized to receive a bone marrow or a peripheral blood transplantation. Haematologica 2002;87:1281-5.

9. Edman L;Larsen J;Hagglund $\mathrm{H}$ et al. Health-related quality of life;symptom distress and sense of coherence in adult survivors of allogeneic stem-cell transplantation. Eur J Cancer Care 2001;10 (2):124-30.

10. Entonen A, Wiren R. Adaptation to severe intestinal GVHD after BMT. EBMT Nurses Group Newsletter 1992;2:15-7

11. Ferrell BR, Grant, MM. Quality of Life Scale: Bone Marrow Transplant. In. Quality of Life from Nursing and Patient Perspectives: Theory, Research, Practice. 2nd edc. Jones and Bartlett Publishers, 2003.

12. Giralt S, Slavin S. New Frontiers in Cancer Therapy: Non-Myeloablative Stem Cell Transplantation (NST). Darwin Scientific Publishing, 2000;159.

13. Grant, M, Ferrell, B, Schmidt, GM, Fonbuena, P, Niland, JC. Measurement of quality of life in bone marrow transplantat survivors. Qual Life Res. 1992;1: 375-84.

14. Heinonen H, Volin L, Uutela A. Gender-associated differences in the quality of life after allogeneic BMT. Bone Marrow Transplant 2001;28:503-9.

15. Heinonen H, Volin L, Uutela A. Quality of life and factors related to perceived satisfaction with quality of life after allogeneic bone marrow transplantation. Ann Hematol 2001;80:137-43.

16. Kouroukis T, Meyer R, Benger A, Marcellus D, Foley R, Browman G. An evaluation of age-related differences in quality of life preferences in patients with non-Hodgkins lymphoma. Leuk Lymphoma 2004;45:2471-6.

17. Mesanyová M, Šimek J. Bone Marrow Transplant from Patients Overview. Prakt Lék 2004;84:536-40

18. Molassiotis A. Further evaluation of a scale to screen for risk of emotional difficulties in bone marrow transplant recipients. J Adv Nurs. 1999;29 (4):922-7.

19. Saleh US, Brockopp DY. Quality of life one year following bone marrow transplantation: psychometric evaluation of the quality of life in bone marrow transplantation survivors tool. Oncol Nurs Forum 2001;28:1457-64. 
20. Slováček L, Slováčková B, Jebavý L. Global Quality of Life in Patients Who Have Undergone the Hematopoietic Stem Cell Transplantation: Finding from Transversal and Retrospective Study. Exp Oncol 2005;27:238-42.

21. So WK, Dodgson J, Tai JW. Fatigue and quality of life among Chinese patient with hematologic malignancy and bone marrow transplantation. Cancer Nurs 2003;26:211-219.

22. The EuroQol Group: EuroQol - a new facility for the measurement of health-related quality of life. Health Policy 1990;16:199-208.

23. Uyl-de Groot CA, Buijt I, Gloudemans IJM, Ossenkoppele GJ, van den Berg HP,
Huijgens PC. Health related quality of life in patients with multiple myeloma undergoing a double transplantation. Eur J Haematol 2005·74:136-43.

24. Wang WQ, Lin GW. Study on quality of life in long-term survivors with acute leukemia in Shanghay. Zhonghua Liu Xing Bing Xue Za Zhi 2003;24:1049-51.

25. Wong R, Giralt SA, Martin T. Reduced-intensity conditioning for unrelated donor hematopoetic stem cell transplantation as treatment for myeloid malignancies in patients older than 55 years. Blood 2003;102:3052-9.

26. Zittoun R, Achard S, Ruszniewski M. Assessement of quality of life during intensive chemotherapy bone marrow transplantation. Psychooncol 1990;8:64-73.

Submitted February 2007. Accepted April 2007.

\section{Corresponding author:}

Ladislav Slováček, M.D., Ph.D., major, University of Defence, Faculty of Military Health Science, Department of Field Internal Medicine, Trebešská 1575, 50001 Hradec Králové 1, Czech Republic, e-mail: ladislav.slovacek@seznam.cz 